\title{
Perbandingan Metode Chaotic Josephus Permutation Matrix dan Metode Kriptografi Hill Cipher untuk Pengamanan Citra Digital
}

\author{
Sayuti Rahman ${ }^{1}$, Zakaria Rivaldi ${ }^{2}$ \\ Prodi Teknik Informatika, Sekolah Tinggi Teknik Harapan \\ Masay.ram@gmail.com
}

\begin{abstract}
ABSTRAK
Seiring dengan perkembangan yang cepat dari komunitas jaringan, pengiriman media digital berupa teks, gambar (citra digital), audio atau video melalui jaringan menghadapi masalah keamanan, dimana citra digital kemungkinan dapat diakses oleh pihak lain yang terhubung pada jaringan tersebut. Keamanan dari citra digital menjadi sangat penting pada banyak area, seperti proteksi privasi dan hak cipta, Untuk mengatasi permasalahan tersebut dapat digunakan dengan kriptografi, metode kriptografi yang sering digunakan yaitu Hill Cipher dan Chaotic Josephus Permutation Matrix, dari pengujian MSE diperoleh informasi bahwa pengaruh kunci pada algoritma Chaotic Josephus Permutation Matrix dan algoritma Hill Cipher sangat bagus karena nilai MSE yang dihasilkan sangat besar, namun Algoritma Hill Cipher memiliki waktu eksekusi yang jauh lebih bagus daripada algoritma Chaotic Josephus Permutation Matrix.
\end{abstract}

\section{Pendahuluan}

Seiring dengan perkembangan yang cepat dari komunitas jaringan, pengiriman media digital berupa teks, gambar (citra digital), audio atau video melalui jaringan menghadapi masalah keamanan, dimana citra digital kemungkinan dapat diakses oleh pihak lain yang terhubung pada jaringan tersebut. Keamanan dari citra digital menjadi sangat penting pada banyak area, seperti proteksi privasi dan hak cipta, keamanan komunikasi dan juga aplikasi militer. Enkripsi adalah sebuah proses transformasi informasi (biasanya disebut sebagai plaintext) menggunakan sebuah algoritma (biasanya disebut sebagai cipher) untuk menghasilkan informasi terenkripsi (biasanya disebut sebagai ciphertext) yang tidak terbaca oleh orang lain, kecuali pemakai yang berhak dengan pengetahuan khusus (biasanya disebut sebagai kunci[3]. Enkripsi telah lama digunakan oleh militer dan pemerintah untuk menyediakan komunikasi rahasia. Skema enkripsi tradisional seperti simple-DES, triple-DES, RSA, IDEA, AES tidak cocok untuk membangun kriptosistem untuk citra digital, karena kapasitas citra digital yang besar dan memiliki redundansi tinggi.

Untuk mengatasi permasalahan tersebut dapat digunakan dengan kriptografi, metode kriptografi yang sering digunakan yaitu Hill Cipher. Hill Cipher adalah metode yang menggunakan sebuah matriks persegi sebagai kunci berukuran (mxm) sebagai kunci untuk melakukan enkripsi dan dekripsi. Dasar teori matriks yang digunakan dalam Hill Cipher antara lain adalah perkalian antar matriks dan melakukan invers pada matriks. Karena menggunakan matriks sebagai kunci, Hill Cipher merupakan algoritma kriptografi kunci simetris yang sulit dipecahkan.

Teknik lainnya yang dapat digunakan adalah pemetaan chaotic yang memiliki beberapa sifat yang bagus yaitu memiliki ciri pengacakan, sangat sensitif terhadap kondisi awal dan sifat acak yang susah diprediksi sehingga cocok untuk . diterapkan pada proses enkripsi data. Namun, metode enkripsi chaotic juga memiliki beberapa kelemahan yaitu sangat rentan terhadap penyerangan struktur dasar, efisiensi yang rendah untuk mengenkripsi keseluruhan citra digital, sifat pengacakan yang buruk dan distribusi yang tidak seragam dari deretan chaos[3].

Berdasarkan alasan diatas, penulis tertarik untuk meneliti dan membandingkan kedua metode tersebut untuk pengamanan citra digital untuk mendapatkan metode tebaik dengan judul "Perbandingan Metode Chaotic Josephus Permutation Matrix dan Metode Kriptografi Hill Cipher untuk Pengamanan Citra Digital”

\section{Citra Digital}

Citra sebagai keluaran suatu sistem perekaman data dapat bersifat optik berupa foto, bersifat analog berupa sinyal-sinyal video seperti gambar pada monitor televisi, atau bersifat digital yang dapat langsung disimpan pada pita magnetik. Menurut presisi yang digunakan untuk menyatakan titik-titik koordinat pada domain spasial atau bidang dan untuk menyatakan nilai keabuaan atau warna suatu citra, maka secara teoritis citra dapat dikelompokkan menjadi empat kelas citra, yaitu citra kontinukontinu, kontinu-diskrit, diskrit-kontinu, dan diskritdiskrit, di mana label pertama menyatakan presisi dari titik-titik koordinat pada bidang citra sedangkan label kedua menyatakan presisi nilai keabuan atau warna. Kontinu dinyatakan dengan presisi angka tak terhingga, sedangkan diskrit dinyatakan dengan presisi angka terhingga. 
Komputer digital bekerja dengan angka-angka presisi terhingga, dengan demikian hanya citra dari kelas diskrit-diskrit yang dapat diolah dengan komputer, citra dari kelas tersebut lebih dikenal sebagai citra digital. Citra digital merupakan suatu array dua dimensi atau suatu matriks yang elemen-elemennya menyatakan tingkat keabuan dari elemen gambar, jadi informasi yang terkandung bersifat diskrit. Citra digital tidak selalu merupakan hasil langsung data rekaman suatu sistem. Kadang-kadang hasil rekaman data bersifat kontinu seperti gambar pada monitor televisi, foto sinar-X, dan lain sebagainya. Dengan demikian untuk mendapatkan suatu citra digital diperlukan suatu proses konversi, sehingga citra tersebut selanjutnya dapat diproses dengan komputer.

\section{Chaotic Josephus Permutation Matrix (CJPM)}

Berdasarkan pada deretan permutasi chaotic Josephus (Chaotic Josephus Permutation Sequence/CJPS), sebuah Chaotic Josephus Permutation Matrix (CJPM) dapat dihasilkan dengan menggunakan berbagai cara. Cara langsung untuk menghasilkan sebuah CJPM dengan menggunakan sebuah CJPS adalah dengan menyusun elemen CJPS ke dalam sebuah matriks seperti terlihat pada gambar 1 berikut:

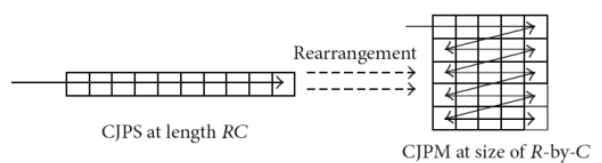

Gambar 1 Ilustrasi Transformasi dari CJPS ke CJPM

Sumber: Gelan Yang, et. al, 2014

Oleh karena itu, sebuah CJPM ditentukan dengan menggunakan kumpulan parameter yang sama yang mengontrol CJPS. Untuk menekankan sifat matriks, parameter $\mathrm{t}$ pada CJPS diganti dengan dua parameter yaitu tinggi $\mathrm{R}$ dan lebar $\mathrm{C}$, dimana $\mathrm{t}=$ RC. Hal yang sama, sebuah CJPM secara unik ditentukan oleh sekumpulan parameter $(\mathrm{R}, \mathrm{C}, \mathrm{s}, \mathrm{n}$ $\left., \mathrm{X}_{0}, \mathrm{r}, \mathrm{m}\right)$ seperti halnya untuk sebuah CJPS. Secara matematis, dapat disimbolkan sebagai berikut:

(Gelan Yang, et. al, 2014).

$$
\mathrm{M}=\mathrm{CJPM}\left(\mathrm{R}, \mathrm{C}, \mathrm{s}, \mathrm{n}, \mathrm{X}_{0}, \mathrm{r}, \mathrm{m}\right)
$$

\section{Hill Cipher}

Hill Cipher merupakan penerapan aritmatika modulo pada kriptografi. Teknik kriptografi ini menggunakan sebuah matriks persegi sebagai kunci yang digunakan untuk melakukan enkripsi dan dekripsi. Teknik kriptografi ini diciptakan dengan maksud untuk dapat diciptakan cipher (kode) yang tidak dapat dipecahkan menggunakan teknik analisis frekuensi.[4].

Sejak kekaisaran Romawi, kriptosistem yang lebih rumit dikembangkan oleh orang seperti oleh ahli Matematika Italia Leon Battista Alberti (lahir pada tahun 1404), Matematikawan Jerman Johannes Trithernius (lahir pada tahun 1492), seorang kriptographer dan diplomat Perancis Blaise de Vigenére (1523-1596), Lester S. Hill, yang menemukan Hill Cipher (Hill Cipher) pada tahun 1929. Hill Cipher merupakan jenis lain dari polygraphic cipher. Sandi ini mengenkripsi suatu string huruf menjadi bentuk string yang lain dengan panjang yang sama. Teknik Hill Cipher dikembangkan oleh Lester S. Hill pada Hunter College dan dipublikasikan pada Americian Mathematical Monthly, Volume 36, Issue 6 (Juni-Juli, 1929) halaman 306 - 312. Hill Cipher menggunakan matriks untuk mentransformasi string berupa blok huruf.

Hill Cipher berdasarkan pada aljabar linier dan seperti sandi Vigenére, Hill Cipher merupakan block cipher. Sandi ini dapat dipecahkan dengan known-plaintext attacks tetapi tahan melawan ciphertext-only attack. Cara kerja sandi ini berdasarkan atas perkalian matriks dengan menggnakan sebuah kunci K.

Penjelasan mengenai Hill Cipher ini dapat diuraikan sebagai berikut: Misalkan $\mathrm{m}$ adalah bilangan bulat positif dan $\mathrm{P}=\mathrm{C}=(\mathrm{Z} 26)^{\mathrm{m}}$ dan misalkan $\mathrm{K}=\left\{\begin{array}{lll}m & x & m\end{array}\right.$ merupakan matriks yang nilai elemennya terdiri dari $\mathrm{Z}_{26}$, maka untuk suatu kunci $\mathrm{K}$, dapat didefiniskan sebagai $\mathrm{e}_{\mathrm{k}}(x)=\mathrm{K} \times \bmod 26$ dan $\mathrm{d}_{\mathrm{k}}(\mathrm{y})=\mathrm{K}^{-1}$ y Mod 26 dimana semua operasi dilakukan dalam matriks $\mathrm{Z}_{26}$

Karena $\mathrm{K}^{-1}$ dengan mudah dapat dihitung dari K, maka Hill Cipher merupakan suatu kriptosistem asimetrik. Hill Cipher juga merupakan blok cipher linier umum. Suatu blok cipher linier dapat dengan mudah dipecahkan yang dikenal cara known-plaintext attacks. Maka bagi penyerang yang mengetahui beberapa contoh plaintext dengan enkripsi yang berhubungan, tidaklah sulit baginya untuk mencari kunci yang dipakai untuk mengenkripsi plaintext tersebut. Bahkan enkripsi dengan teks yang tidak diketahui dapat didekripsi tanpa harus memerlukan usaha yang sulit. Metode dari perhitungan frekuensi sering dipakai untuk usaha ini. Metode ini mengeksplorasi perulangan (redundancy) dari bahasa alami yang dipakai sebagai plaintext pada pesan.

Sebagai contoh, pada banyak bahasa huruf "E" sering muncul dengan persentasi dalam bahasa Inggris mencapai $12,31 \%, 15,87 \%$ untuk bahasa Perancis, dan bahkan $18,46 \%$ dalam bahasa Jerman. Penjelasan cara kerja dari Hill Cipher dapat disederhanakan dengan cara seperti ini. Misalkan K merupakan sebuah matriks kunci $m \times m$ yang merupakan representasi dari suatu persamaan linier. 
Ciphertext $(\mathrm{C})$ dan plaintext $\mathrm{p}$ merupakan matriks $m$ $\times 1$. Maka didapat persamaan untuk menghasilkan ciphertext sebagai berikut:

$$
\begin{gathered}
\mathrm{C}=\mathrm{K} \cdot \mathrm{P}(\bmod 26) \\
\left(\begin{array}{l}
C_{1} \\
C_{2} \\
C_{3}
\end{array}\right)=\left(\begin{array}{lll}
k_{11} & k_{12} & k_{13} \\
k_{21} & k_{22} & k_{23} \\
k_{31} & k_{32} & k_{33}
\end{array}\right)\left(\begin{array}{l}
P_{1} \\
P_{2} \\
P_{3}
\end{array}\right) \bmod 26
\end{gathered}
$$

Dekripsi memerlukan kunci $\mathrm{K}$ yang bersifat invertible. Contohnya $\mathrm{K} \cdot \mathrm{K}^{-1}(\bmod 26)=\mathrm{I}$ dimana I merupakan matriks identitas. Karena $\mathrm{C}=\mathrm{K}$. P Mod 26 maka $\mathrm{K}=\mathrm{C} . \mathrm{P}^{-1}$ Mod 26 Tidak semua plaintext bersifat invertible (dapat dibalik kembali). Sandi Caesar, Hill Cipher, dan sandi Playfair semua bekerja dengan sebuah alphabet tunggal saat disubstitusi.

\section{Analisis Proses Chaotic Josephus Permutation Matrix}

Analisis proses merupakan tahapan proses pembuatan sistem secara sistematis sebelum terbentuk sebuah aplikasi dimana akan diketahui proses kerja awal sistem sampai sistem tersebut selesai. Secara garis besar, proses kerja dari sistem dapat dibagi menjadi 2 bagian seperti diilustrasikan pada gambar 2 dan gambar 3 .

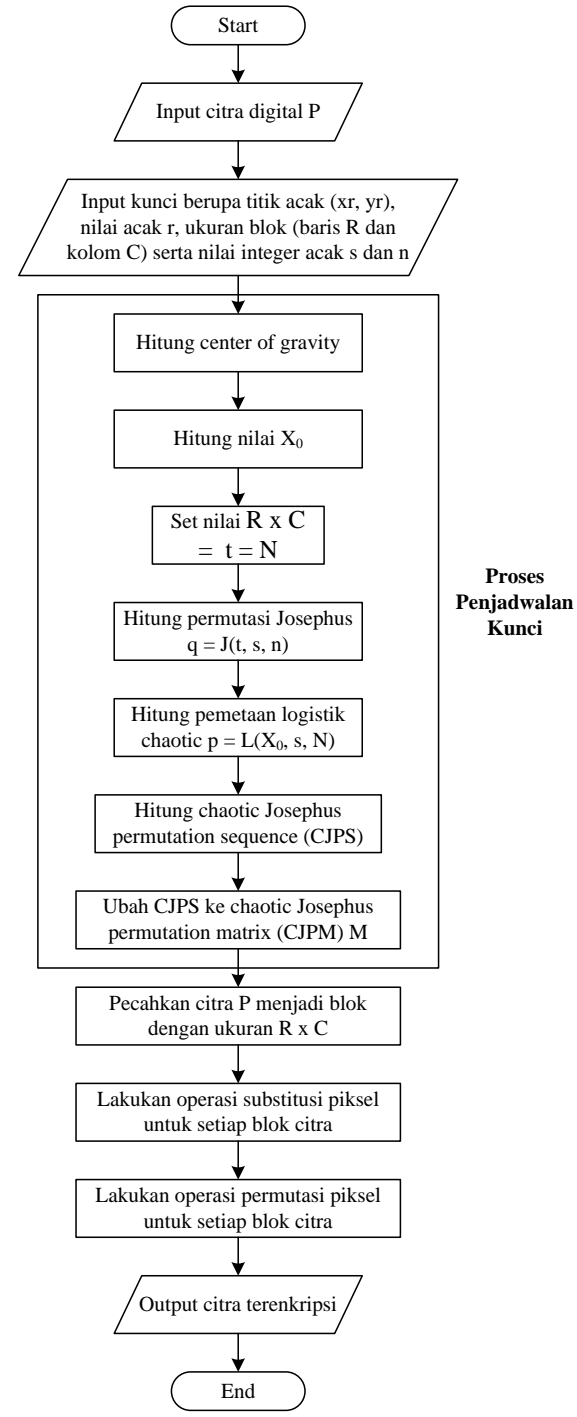

Gambar 2 Flowchart dari Proses Enkripsi Metode Chaotic Josephus Permutation Matrix 


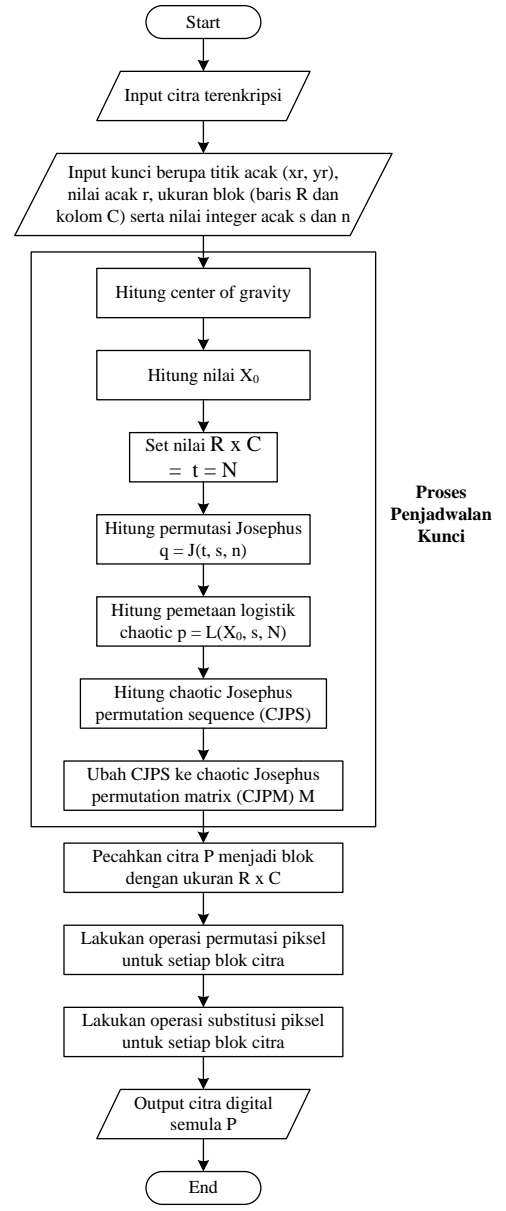

Gambar 3 Flowchart dari Proses Dekripsi Metode Chaotic Josephus Permutation Matrix

\section{Analisis Proses Hill Cipher}

Metode Hill Cipher sebenarnya dipakai untuk proses penenkripsian dan pendekripsian pada teks, tetapi dapat juga dipakai pada citra digital karena citra merupakan kumpulan dari piksel-piksel. Berdasarkan hasil analisa terhadap metode yang digunakan, maka penulis melakukan perhitungan enkripsi dan dekripsi dengan menggunakan metode Hill Cipher pada citra yang nantinya akan diterapkan didalam program yang dibuat. Secara garis besar, proses kerja dari sistem dapat dibagi menjadi 2 bagian seperti diilustrasikan pada gambar 4 dan gambar 5.

\section{Proses Enkripsi}

Langkah proses enkripsi dari metode Hill Cipher ini dapat dijabarkan sebagai berikut:

1) Input citra digital $P$.

2) Input matriks kunci ukuran $2 \times 2$. Pilih suatu matriks kunci $\mathrm{K}$ yang berupa matriks bujur sangkar, matriks kunci merupakan matriks identitas $\left[\begin{array}{ll}1 & 0 \\ 0 & 1\end{array}\right]$. Format dalam pembentukan matriks kunci adalah $\left[\begin{array}{ll}0 & 1 \\ 1 & 0\end{array}\right]$. Kombinasi matriks kunci yang dapat dipakai adalah sebagai berikut:

$0=16,32,48,64,80,96,112,128,144$, 160, 176, 192, 208, 224, 240. $1=127,129,255$.

3) Kelompokkan barisan piksel yang didapat ke dalam beberapa blok vektor $\mathrm{P}$ yang panjangnya sama dengan ukuran matriks $\mathrm{K}$.

4) Hitung $C=K . P(\bmod 256)$ untuk tiap vektor $\mathrm{P}$.

5) Output citra terenkripsi.

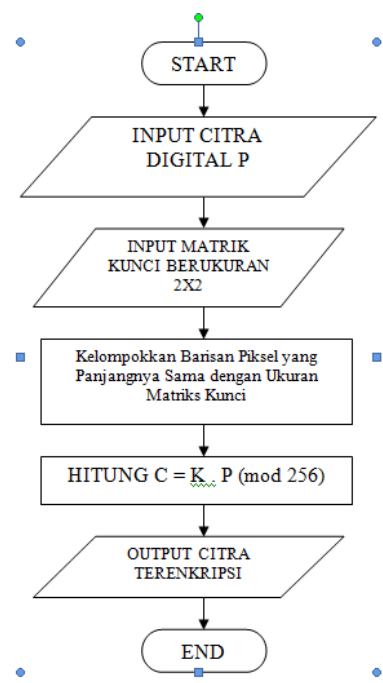

Gambar 4 Flowchart dari Proses Enkripsi metode Hill Cipher

2. Proses Dekripsi

Langkah proses dekripsi dari metode Hill

Cipher ini dapat dijabarkan sebagai berikut:

1) Input citra digital terenkripsi $P$.

2) Input matriks kunsi berukuran $2 \times 2$.

3) Kelompokkan barisan piksel yang didapat ke dalam beberapa blok vektor $\mathrm{C}$ yang panjangnya sama dengan ukuran matriks $\mathrm{K}$.

4) Hitung $P=K_{\text {baru }} \cdot C(\bmod 256)$ untuk tiap vektor $\mathrm{C}$.

5) Output citra hasil dekripsi. 


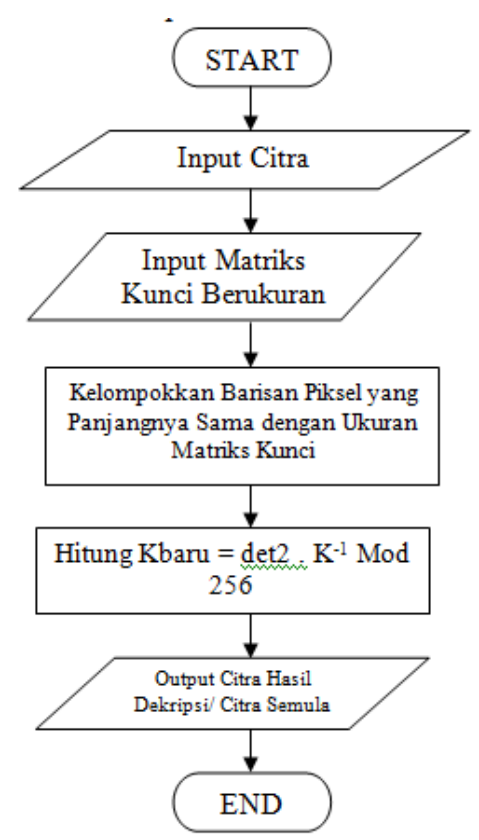

Gambar 5 Flowchart dari Proses Dekripsi metode Hill Cipher

\section{Proses Enkripsi CJPM}

Proses Enkripsi dengan menggunakan metode Chaotic Josephus Matrix ini dapat dilakukan dengan mengklik menu proses lalu klik menu 'Enkripsi CJPM sehingga sistem akan menampilkan form Enkripsi CJPM lalu 'Proses Enkripsi Citra' untuk memulai proses enkripsi. Tampilan form Proses Enkripsi akan terlihat seperti pada gambar berikut:

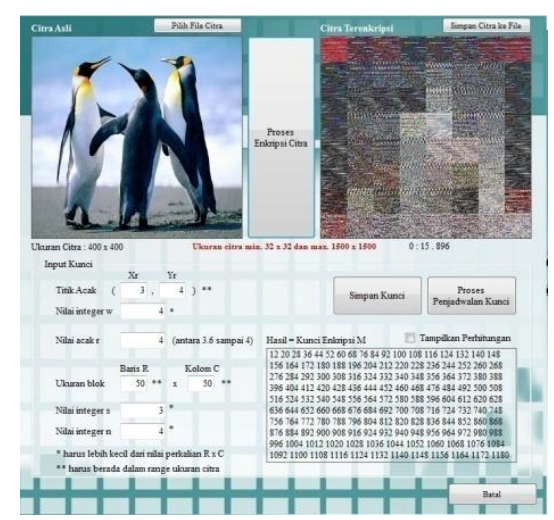

Gambar 6 Tampilan Form Proses Enkripsi CJPM Setelah Menghasilkan Proses Enkripsi

Setelah itu klik tombol 'simpan citra ke file' untuk menyimpan citra terenkripsi, maka tampilan akan terlihat seperti pada gambar berikut:

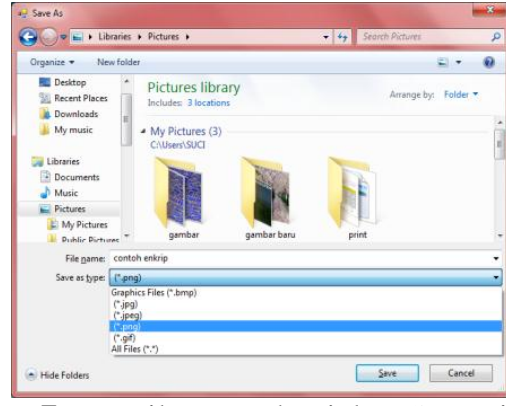

Gambar 7 Tampilan Kotak Dialog Save File Citra Terenkripsi

Untuk mengektraksi klik tombol 'Proses Dekripsi Citra' untuk memulai proses dekripsi sehingga sistem akan menampilkan form 'Dekripsi' seperti terlihat pada gambar berikut:

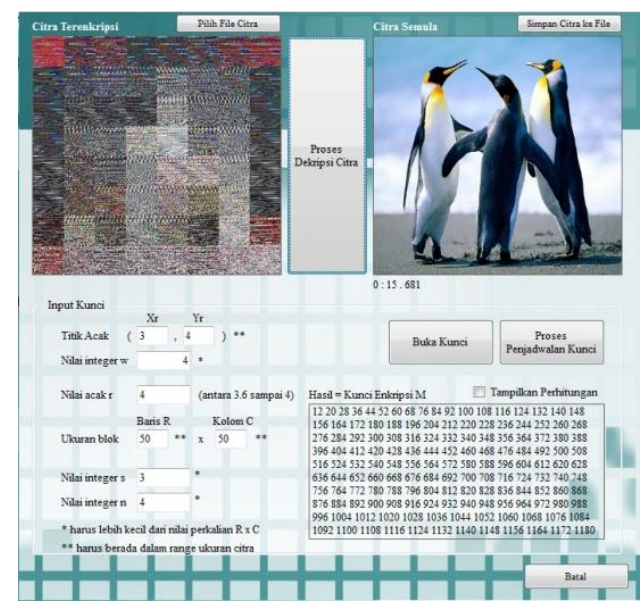

Gambar 8 Tampilan Setelah Proses Dekripsi CJPM Dilakukan

\section{Proses Hill Chiper}

Untuk proses hill chipper dengan memasukan kunci dan citra, Kunci yang dimasukkan adalah matriks pesergi dengan k1 : 224, k2 : 129, k3 : 127 dan k4 : 240, kemudian klik tombol Enkripsi sehingga sistem akan memulai proses enkripsi terhadap citra input. Hasil proses enkripsi dapat dilihat pada gambar berikut: 


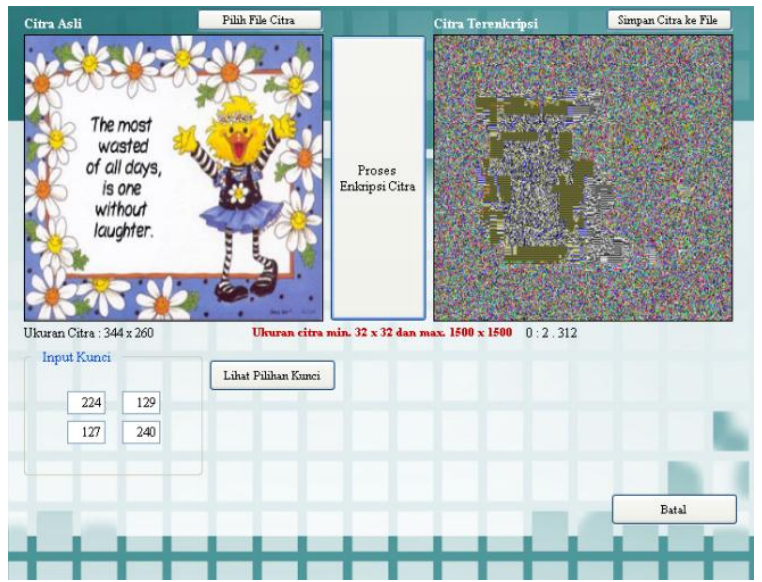

Gambar 9 Tampilan Form Enkripsi Hill Cipher Setelah Proses Enkripsi

Untuk proses ekstaksi dengan memasukan citra yang sudah di enkripsi dan kunci yang sama, Kunci yang dimasukkan adalah matriks pesergi dengan $\mathrm{k} 1$ : 224, k2 : 129, k3 : 127 dan k4 : 240. Kemudian klik tombol Dekripsi Citra sehingga sistem akan memulai proses dekripsi terhadap citra input. Hasil proses dekripsi dapat dilihat pada gambar berikut:

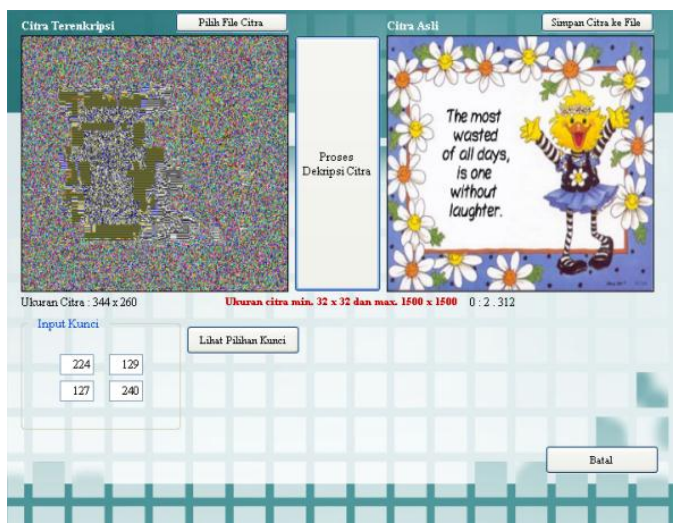

Gambar 10 Form Dekripsi Hill Cipher Setelah Proses Dekripsi

\section{Perbandingan Titik Pasti antara Metode CJPM dengan Metode $\mathrm{Hill}$ Cipher}

Untuk dapat melihat hasil perbandingan dari pengujian Titik Pasti antara Metode CJPM dengan Metode Hill Cipher maka penulis merangkumnya ke dalam tabel berikut ini:

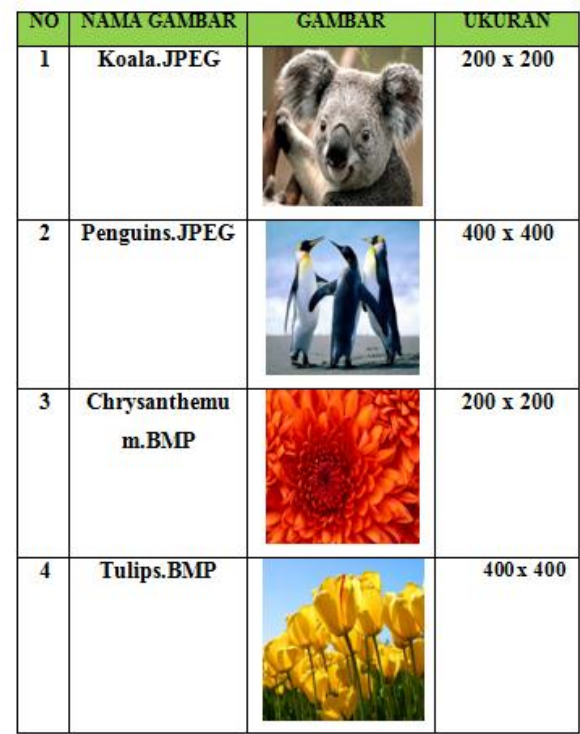

Hasil Pengujian Titik Pasti antara Metode CJPM dengan Metode Hill Cipher

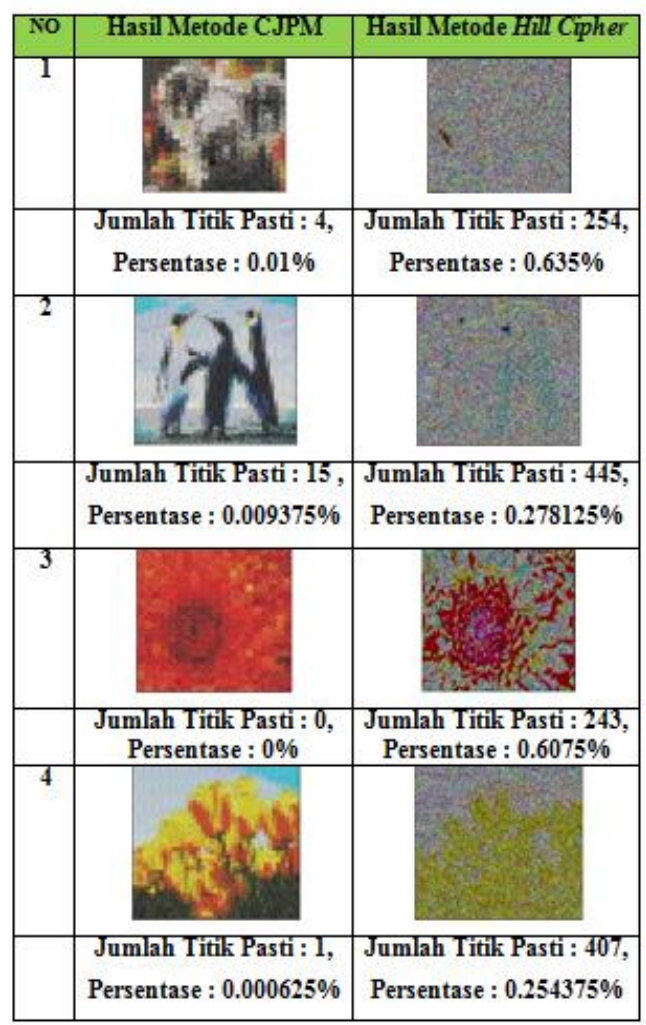

\section{Penutup}

Setelah menyelesaikan pembuatan perangkat lunak ini, penulis dapat menarik beberapa kesimpulan sebagai berikut:

1. Perubahan kecil terhadap nilai input kunci yang digunakan pada algoritma pengacakan citra Chaotic Josephus Permutation Matrix ini memiliki pengaruh yang cukup bagus terhadap citra hasil enkripsi, hal ini terbukti dari nilai mse 
yang jauh lebih besar dari $30 \mathrm{db}$, bekisar antara $674.6993875 \mathrm{db}$ sampai $9190.9861833 \mathrm{db}$.

2. Dari pengujian MSE diperoleh informasi bahwa pengaruh kunci pada algoritma Chaotic Josephus Permutation Matrix dan algoritma Hill Cipher sangat bagus karena nilai MSE yang dihasilkan sangat besar.

3. Algoritma Hill Cipher memiliki waktu eksekusi yang jauh lebih bagus daripada algoritma Chaotic Josephus Permutation Matrix.

4. Pada algoritma Hill Cipher, pemilihan kunci sangat berpengaruh terhadap hasil enkripsi dan kunci yang dapat digunakan pada algoritma Hill Cipher sangat terbatas sehingga menyebabkan sekuritas dari algoritma Hill Cipher ini menjadi kurang bagus.

5. Dari pengujian Titik Pasti diperoleh informasi bahwa algoritma Chaotic Josephus Permutation Matrix lebih bagus dibandingkan algoritma Hill Cipher, karena algoritma Chaotic Josephus Permutation Matrix memiliki jumlah titik pasti yang lebih sedikit.

\section{References}

[1] Anton, H. dan C. Rorres 2005. Aljabar Linear Elementer, Edisi Kedelapan - Jilid 2, Versi Aplikasi, Penerbit Erlangga.

[2] Blackledge, J., M. Ahmad dan O. Farooq. 2010. Chaotic Image Encryption Algorithm Based on Frequency Domain Scrambling, Dublin Institute of Technology, ARROW@DIT, School of Electrical Engineering Systems.

[3] Gelan Yang, Huixia Jin dan Na Bai. 2014. Image Encryption Using the Chaotic Josephus Matrix, Mathematical Problems in Engineering, Volume 2014, China.

[4] Hamdani, Anindita Septiani, and Fajri Nugraha. 2014. Penggunaan Metode Hill Cipher untuk Kriptografi pada Citra Digital. Kalimantan Timur: Jurusan Ilmu Komputer, Fakultas MIPA, Universitas Mulawarman.

[5] Jubilee Enterprise. 2010. Cara Inspiratif Berburu Ide Untuk Blog. Jakarta: PT. Elex Media Komputindo.

[6] Liu Xiangdong, Zhang Junxing, Zhang Jinhai, He Xiqin. 2008. Image Scrambling Algorithm Based on Chaos Theory and Sorting Transformation, IJCSNS International Journal of Comptuer Sicence and Network Security, Vol 8 No.1.

[7] Purnawan, Muharram Candra. 2014. Analisa Performa Algoritma Hill Cipher Terhadap Varian Encoding Citra Digital. Semarang: FASILKOM Universitas Dian Nuswantoro.

[8] Roza, Astri Eldifa. 2014. Aplikasi Pengamanan Citra Digital Menggunakan Metode Kriptografi Hill Cipher. Medan: Program Studi Informatika, Sekolah Tinggi Teknik Harapan.
[9] Susanto, Alvin. 2013. Penerapan Teori Chaos di Dalam Kriptografi. Bandung: Program Studi Informatika, Institut Teknologi Bandung.

[10] T. Sutoyo, Edy Mulanto, Vincent Suhartono, Oky Dwi Nurhayati, Wijanarto. 2009. Teori Pengolahan Citra Digital. Yogyakarta: Penerbit Andi.

[11] Yicong Zhou, Karena Panetta dan Sos Agaian. 2008. An Image Scrambling Algorithm Using Parameter Based M-Sequences, USA.

[12] Yullinda, C.D. 2008. Implementasi Watermarking dengan Metode Discrete Cosine Transform (DCT) pada Citra Digital, Digital Library-Perpustakaan Pusat UNIKOM.

[13] Zhu Liehuang, Li Wenzhou, Liao Lejian dan Li Hong. 2006. A Novel Image Scrambling Algorithm for Digital Watermarking Based on Chaotic Sequence. IJCSNS, International Journal of Computer Science and Network Security, Vol 6, No. 8B. 